\title{
Events: entre la práctica artística y la práctica curatorial
}

\author{
MAURO CACCIATORE Universidad Nacional de las Artes, Argentina
}

ORCID 0000-0002-9983-5694

cacciatoremaurose@gmail.com

\section{Resumen}

Las colaboraciones de Merce Cunningham con artistas innovadores de todas las disciplinas han redefinido la manera de experimentar las artes visuales y del espectáculo, al proponer una gran cantidad de desvíos respecto de otras prácticas escénicas e incluso desarrollando novedosos dispositivos de presentación de su propio material. Me propongo abordar el formato denominado Event (Evento) cuyo surgimiento se encuentra ligado a una peculiar forma de presentar su trabajo fuera del espacio escénico tradicional. Abordaré los planteos sobre género y estilo realizados por Oscar Steimberg para reflexionar sobre el estatuto de este formato poniendo en paralelo la serie Beacon Events y el Park Avenue Armory Event. La primera propuesta fue realizada por Cunningham y la segunda estuvo a cargo de Robert Swinston, factor que nos permitiría abordar dos posibilidades con relación al mismo formato: sus particularidades como práctica artística y las implicancias de analizarlo como práctica curatorial. A partir de la confrontación de estos casos, desarrollaré los posibles cruces entre los aspectos curatoriales de una práctica artística (en el caso de las creaciones de Cunningham) y los aspectos artísticos de una práctica curatorial (con relación al uso de esta modalidad por parte del Merce Cunningham Trust).
Palabras clave: Event / curaduría / coreografía / género / previsibilidad

\section{Events: between artistic practice and curatorial practice}

\section{Abstract}

Merce Cunningham's contributions with innovative artists of all disciplines have redefined the way of experiencing the visual and performing arts, proposing a number of deviations from other performance practices and even developing novel devices for presenting his own material.

I propose to investigate the format called Event whose emergence is connected to a peculiar way of presenting their work outside the traditional performance space. I will work with Oscar Steimberg's proposals on genre and style to reflect on the status of this format, putting the Beacon Events series and the Park Avenue Armory Event in parallel. The first proposal was made by Cunningham and the second by Robert Swinston, a factor that would allow us to consider two possibilities in relation to the same format: its particularities as an artistic practice and the implications of analysing it as a curatorial practice. From the confrontation of these cases, I will explore the possible crossovers between the curatorial aspects of an artistic practice (in the case of Cunningham's creations) and the

Recibido: 28/2/2021. Aceptado: 11/3/2021

Para citar este artículo: Cacciatore, M. (2021). Events: entre la práctica artística y la práctica curatorial. 
artistic aspects of a curatorial practice (in relation to the use of this format by the Merce Cunningham Trust).
Key words: Event / curation / choreography / genre / predictability

La Merce Cunningham Dance Company (MCDC) ha tenido una importante repercusión en el arte de vanguardia norteamericano desde su creación en 1953. La concepción del espacio, el tiempo y la tecnología sumamente radical que Merce Cunningham desarrolla, le permite consolidar un estilo único que da cuenta de las posibilidades casi infinitas del movimiento humano. Sus colaboraciones con artistas innovadores de todas las disciplinas durante más de cincuenta años han redefinido la manera de experimentar las artes visuales y del espectáculo, proponiendo una gran cantidad de desvíos respecto de otras prácticas escénicas e incluso desarrollando novedosos dispositivos de presentación de su propio material.

Me propongo en este artículo abordar el formato denominado Event (Evento) cuyo surgimiento se encuentra ligado a una peculiar forma de presentar su trabajo fuera del espacio escénico tradicional. Abordaré los planteos sobre género y estilo realizados por Oscar Steimberg para reflexionar sobre el estatuto de este formato poniendo en paralelo dos casos diferentes. Por un lado, la serie denominada Beacon Events, una colaboración entre la MCDC: Dia Art Foundation. Por el otro, el Park Avenue Armory Event, presentación final que realizó la MCDC antes de disolverse. En estas dos propuestas, más allá de las particularidades que cada una pueda tener, hay un factor que resulta fundamental para este análisis y es que el primero fue realizado por Cunningham y el segundo estuvo a cargo de Robert Swinston (bailarín de la MCDC desde 1980, asistente coreográfico desde 1992 y al momento del montaje, director coreográfico del Merce Cunningham Trust — MCT—), factor que nos permitiría abordar dos posibilidades en relación con el mismo formato: sus particularidades como práctica artística y las implicancias de analizarlo como práctica curatorial. A partir de la confrontación de estos casos, desarrollaré los posibles cruces entre los aspectos curatoriales de una práctica artística (en el caso de las creaciones de Cunningham) y los aspectos artísticos de una práctica curatorial (con relación al uso de esta modalidad por parte del MCT.

Los Events surgen durante la gira mundial de la MCDC en 1964. Entre compromisos en Venecia y Mannheim (Alemania), Cunningham fue invitado a presentarse en el Museum des 20 Jahrhunderts (Museo del Siglo XX) cuyo edificio de vidrio y acero fue diseñado por Karl Schwanzer para el Pabellón austríaco de la Feria Mundial de Bruselas de 1958, luego desmantelado y reconstruido en el Schweizer Garten de Viena en 1962. Al no contar con un teatro convencional, se le ofrece al coreógrafo un gran espacio abierto en la planta baja del pabellón. Dada la imposibilidad de realizar obras del repertorio regular sin un escenario, Cunningham ideó una presentación continua de diferentes segmentos de sus obras organizados para esa ocasión particular. La música no fue la que acompañaba originalmente a los segmentos realizados, sino que en su lugar se utilizaron las líneas de percusión del Atlas Eclipticalis de John Cage (1961). El público fue ubicado en tres lados del espacio y en una galería superior, el cuarto lado era una pared de vidrio que daba al jardín de esculturas del museo. Esta presentación de aproximadamente noventa minutos fue llamada Museum Event $N^{\circ} 1$.

Lo particular de estos programas es que se componen de extractos de diversas obras del coreógrafo (aunque también podían incluir materiales nuevos creados específicamente para la 
ocasión) preparados con antelación según una metodología que los ordena por azar que nunca se repite exactamente. La unión de estas partes puede darse en continuidad (una secuencia tras otra) y en simultaneidad (una secuencia junto a otra). Las coreografías son seleccionadas especialmente para cada representación en función del espacio y de los artistas (plásticos, músicos, iluminadores, vestuaristas, etc.) que intervienen de manera colaborativa con la totalidad de la obra a modo de instalación. Generalmente los bailarines no escuchan la música ni conocen las características de las otras áreas colaborativas que formarán parte hasta el mismo día de la función. El azar es un elemento presente en todas las coreografías de Cunningham y convierte cada Event en una pieza única e irrepetible.

Douglas Crimp se refiere a estos ensamblajes como «verdaderas piezas de ocasión» (2008:350, traducción propia) y da cuenta de cómo con el paso de los años se han convertido en una de las formas características que adopta la coreografía de Cunningham, al punto que le reclamaban casi la misma dedicación que las obras del repertorio. La flexibilidad que presentan permite que puedan ser ejecutados en cualquier tipo de circunstancia, a tal punto que a lo largo de su historia la MCDC ha realizado casi ochocientos Eventos en espacios no convencionales (como museos, gimnasios, escenarios al aire libre y espacios tan disímiles como la estación Grand Central o las ruinas de Persépolis) y en teatros de proscenios regulares (como el Joyce, la Brooklyn Academy of Music, así como en el ex estudio de Cunningham en Westbeth, el complejo de viviendas para artistas de Nueva York).

Pese a que estas construcciones se conforman como estructuras discursivas autónomas, a menudo no tienen sus propios vestuarios, y la música es improvisada, generalmente por varios músicos que trabajan en conjunto. Además, si bien predominan fragmentos de obras del propio repertorio, a diferencia de ellas no tienen títulos (durante mucho tiempo los Events fueron enumerados pero luego esta práctica se interrumpió) y tampoco figuran en la cronología de sus obras.

Los Eventos, más que presentarse como una obra propiamente dicha, aparecen como un collage de segmentos de obras existentes que pueden ser realizados sin necesidad de una escenografía o vestuario particular y tampoco sin recurrir a escenarios convencionales. Al referirse a este tipo de construcciones, Cunningham solía diferenciarlas de aquello que sucede en un teatro al asistir a un espectáculo específico o un programa compuesto por diferentes obras, cada una autónoma. En este caso, los espectadores se sientan en su ubicación y observan la obra como una unidad de sentido, una entidad que más allá de la complejidad de su construcción y la dificultad que implique para ser abordada, sigue funcionando como una obra. Según Crimp, «An Event, by contrast, is not a work; it is an accumulation of fragments that are impossible to see as an entity - not a dance but dancing» (2012:11). Al considerarse los Events como una acumulación de fragmentos, resulta complejo otorgarle ese valor de entidad, lo que implica el "not a dance but dancing» es que estas construcciones no se presentan como una obra sino simplemente como danza.

Cunningham fue inspirado por el uso de metodologías de azar que Cage empleaba (como tirar un dado o consultar el I Ching) para determinar la estructura de sus obras, la duración de las secciones, el número de bailarines involucrados, sus entradas, lugar en el escenario frente al que se organizarían y salidas. Estas innovaciones implicaron en ese momento una carga inusual para el espectador ya que la coreografía no dirigía su mirada ni otorgaba pistas sobre cómo mirarla. Al concebir la coreografía de manera aislada de la música, de la escenografía y de los vestuarios para unirlos al momento de la presentación, se abre la posibilidad de que las relaciones entre estos factores sean imprevistas. 


\section{Beacon Events}

Los Beacon Events son el resultado de una colaboración de la MCDC con Dia: Beacon-Riggio Galleries. El museo de la Dia Art Foundation tiene en su poder una colección de arte contemporáneo desde la década de 1960 hasta la actualidad. Está situado a orillas del río Hudson en Beacon (Nueva York) y ocupa la antigua fábrica de impresión de cajas de Nabisco que fue renovada por el artista Robert Irwin y los arquitectos Alan Koch, Lyn Rice, Galia Solomonoff y Linda Taalman, quienes lograron convertirla en un espacio de galerías abiertas y llenas de luz. En el marco del Hudson Valley Project se presentó una serie de Events, a razón de uno por cada estación del año (otoño, invierno, primavera y verano). Cada programa se realizó dos veces y para cada uno de ellos no solo se seleccionaron distintos músicos, compositores, diseños de iluminación y vestuarios, sino que además cada uno ocupó un espacio particular de la galería. Como es propio de este tipo de propuestas, las presentaciones públicas fueron la primera vez en las que los artistas implicados se unieron.

La primera presentación se llevó a cabo en septiembre de 2007 en la galería dedicada a las Shadows de Andy Warhol; le siguió uno junto a las galerías paralelas que contienen la Equal Area Series de Walter de Maria (enero de 2008); el próximo ocupó dos escenarios, uno dentro del pabellón dedicado a Bruce Nauman y otro en el exterior del mismo (mayo de 2008); el cuarto fue realizado en la galería que contiene la serie Torqued Ellipsis de Richard Serra (julio de 2008), el quinto en la galería dedicada a la obra de John Chamberlain (diciembre de 2008); el sexto en la galería que contiene las obras de Dan Flavin (febrero de 2009); el último en una de las dos galerías que contienen la obra 24 Colors-for Blinky de Imi Knoebel. Muchos de los artistas de la colección de Dia fueron amigos y antiguos colaboradores de Cunningham. Cada una de las instalaciones ocupó un sitio desafiante para presentar estos trabajos, los que además se adaptaron al cambio de estaciones y las variaciones de luz que ofrecen los tragaluces del Dia:Beacon.

Con relación al presente análisis, detallaré las principales características de la primer y tercer edición solamente para dar cuenta de la diversidad de estas presentaciones. La primera entrega de los Beacon Events tuvo lugar en la galería dedicada a Shadows (un conjunto de serigrafías de Andy Warhol de 1978). Esta sala es una de las más grandes de la galería (780 metros cuadrados) y cuenta con ingreso de luz solar natural. En ella se ubican diecisiete de los paneles de Warhol colgados hasta el suelo y organizados de borde a borde, como si envolvieran la sala. Allí Cunningham utilizó dos escenarios montados a la altura del borde inferior de las serigrafías ubicados en los segmentos noroeste y sudeste de la sala y conectados entre sí por un pequeño puente. Los músicos David Behrman, John King, Takehisa Kosugi y Christian Wolff estaban situados hacia el centro (a ambos lados del puente), desde donde creaban un entorno auditivo polifónico. Los tonos rojizos de los vestuarios diseñados por Anna Finke (fotógrafa y diseñadora de vestuario de la compañía) generaban un interesante contraste con el conjunto de pinturas y con las paredes blancas de la galería. Si bien se colocaron algunos asientos para los espectadores junto a cada escenario, se alentó a los espectadores a caminar libremente por el área libre, teniendo la posibilidad de ver el Evento de cerca o lejos. Dependiendo de la posición elegida, los espectadores podían no solo ver a aquellos bailarines que estaban bailando, sino también a los que estaban descansando, a los músicos trabajando, otros miembros de la audiencia y por supuesto, las pinturas de Warhol. 
Por su parte, el tercer Evento fue dedicado a Robert Rauschenberg, quien acababa de fallecer. Esta presentación fue realizada en el lado sur del sótano de Dia:Beacon (cuyas puertas fueron abiertas), sucediendo en simultáneo en un escenario interior y otro exterior cubierto por una carpa transparente que lo protegía del clima y a la vez permitía el ingreso de la luz del día. Para ubicar a los espectadores se utilizaron cuatro gradas de aluminio y madera diseñadas por Bruce Nauman. Dos de ellas enmarcaban los lados del escenario al aire libre, las otras dos se ubicaban en el escenario interior, hacia el lado posterior y en un lateral. El público podía sentarse al aire libre o dentro de la galería, en uno de sus sótanos cavernosos y con columnas gigantescas del edificio. También era posible caminar alrededor de los dos escenarios que estaban conectados por una rampa para que los bailarines entraran o salieran. Los músicos David Behrman, Miguel Frasconi, Marina Rosenfeld y Richard Teitelbaum estaban ubicados entre los escenarios. Los vestuarios, que también fueron diseñados por Anna Finke, consistían en mallas enterizas de colores vivos que se volvían marrón oscuro desde la rodilla hacia abajo e incluían en distintas partes algunos estampados impresos. También había una serie de pantalones, camisetas y vestidos diseñados para usarse por sobre las mallas que los bailarines podían utilizar a su gusto, siempre y cuando no interfirieran con los movimientos a ejecutar.

Algunos de los segmentos que Cunningham empleó en esta ocasión corresponden a obras de distintas etapas que por ende, remiten a distintos momentos de su investigación. Otro factor importante es que el escenario exterior era dos veces mayor que el interior, por lo tanto los materiales presentados en cada uno fueron muy disimiles (las secuencias en el interior fueron más compactas y lentas mientras que las del escenario exterior eran más expansivas y rápidas). Para esta ocasión, Cunningham creó un nuevo trío como regalo de despedida para Lisa Boudreau, quien se retiraba de la compañía después de esa actuación. En el escenario exterior aparece un dúo de Canfield (1968), un sexteto de Scramble (1967), un dúo y un trío de Squaregame (1976), entre otras. En el escenario interior aparecen segmentos de Steps (1973), Doubles (1984), un trío de Interscape (2000) y el trío dedicado a Boudreau. Como puede verse, la selección es sumamente variada, tanto en sus fechas de creación como en su conformación. Para la creación de sus Eventos Cunningham recicla su propio material, probándolo en diversas combinaciones que implicarán nuevos entornos espaciales, diferente música, vestuario y guión coreográfico. Los diferentes segmentos de sus obras anteriores son traídos al presente para reconfigurarse en nuevas situaciones e incorporarse a nuevos discursos. Los materiales se presentan como una experiencia diferente de aquella que cierra su sentido a la identificación de lo ya conocido, incluso para aquellos que puedan llegar a identificar a qué obra corresponde determinado fragmento.

\section{Park Avenue Armory Event}

En la primera década del siglo XXI, Cunningham comenzó a utilizar más de un escenario a la vez en ciertos espacios lo suficientemente grandes. De esta manera podía desarrollar otro tipo de distribución espacial de los materiales presentados y además, favorecer la posibilidad de un público móvil. El último Evento que Cunningham creó se realizó en dos escenarios montados en el Rockefeller Park, junto al río Hudson. Cunningham murió el 26 de julio de 2009, solo unos días antes de la programación del Evento, por lo que la actuación se convirtió en un homenaje simbólico para él. Tras su muerte y siguiendo el Legacy Plan (elaborado de forma conjunta por el artista y un grupo de personas de su confianza) la MCDC se embarcó en febrero de 2010 en el 
Legacy Tour, una gira mundial de dos años donde se interpretaron dieciocho obras de repertorio representativas de su carrera. El Legacy Tour y la MCDC llegaron a su fin en la ciudad de Nueva York con las seis actuaciones de Park Avenue Armory Event, presentación que funcionó como una retrospectiva de cincuenta años de creación desde Rune (1959) hasta Nearly 90 (2009).

El Park Avenue Armory es uno de los espacios interiores sin obstrucciones más grandes de Nueva York, con 90 metros de largo y 60 metros de ancho con un techo abovedado soportado por arcos de hierro forjado. En ese espacio se montaron tres escenarios elevados rodeados de focos, seis plataformas de un piso para los espectadores y un estrado para los músicos. Para acompañar este Evento se encargaron cuatro composiciones musicales separadas. El set escenográfico diseñado por Daniel Arsham estaba formado por grupos de esferas blancas que colgaban del techo y brillaban gracias a la iluminación de Christine Shallenberg. Anna Finke creó mallas enterizas serigrafiadas con fotografías de Westbeth y de la ciudad tomadas desde las ventanas del estudio.

Los catorce bailarines que integraban la MCDC se movieron entre los tres escenarios elevados a lo largo de la inmensa sala del Armory. La mayoría de los músicos estaba en una especie de tribuna y seis de ellos, con sus instrumentos de bronce, fueron colocados en lo alto. Los más de mil espectadores que asistieron podían moverse de un lugar a otro u ocupar sillas que rodeaban cada escenario permitiéndoles concentrarse en un único espacio. Otros estaban en plataformas elevadas que les permitían observar lo que sucedía en los escenarios distantes. Solo para esta ocasión, los bailarines pudieron elegir lo que deseaban bailar. Las elecciones consistieron en su mayoría de solos, dúos y tríos ubicados en los tres escenarios, los que fueron secuenciados con otros extractos y completados con secciones grupales organizadas por Robert Swinston.

Los Events son una de las formas características en las que la obra de Cunningham sigue circulando en la actualidad. Por fuera de las reposiciones que solicitan algunas compañías de obras específicas del coreógrafo, estas construcciones son una de las estrategias empleadas por el MCT para hacer extensiva la obra del artista a nuevas generaciones de bailarines y espectadores. Cabe destacar que no se realizan reposiciones de Eventos ya realizados, sino que se emplea la misma metodología para desarrollar nuevas construcciones. De esta manera, el Park Avenue Armory Event aparece como un claro ejemplo de cómo trasferir al trabajo curatorial un determinado modelo de investigación de obra que hace uso de una específica forma de seleccionar y organizar cierto patrimonio, que mantiene vigente su producción de sentido al insertarlo en un discurso/obra diferente del original y que permite mantener vigentes los rasgos de discontinuidad y dislocación presentes en las creaciones propias del artista.

Si tomamos su comienzo podremos observar en un primer escenario a Andrea Weber ejecutando un solo de Way Station (2001) cuyo material contiene una sucesión de movimientos sumamente lentos y equilibrios en complejas posiciones. Con la entrada de Brandon Collwes, este solo se convierte en un dúo de la misma obra. No está de más comentar que el espacio escénico de la obra original contiene una serie de esculturas de Charles Long que en esta construcción no fueron incluidas. Mientras tanto en otro escenario encontraremos un septeto interpretando la sección final de Fielding Sixes (1980), obra conformada por sesenta y cuatro frases de movimiento en un rápido compas de seis tiempos. Las frases de esta obra se caracterizan por su amplio recorrido espacial y por contar con abundantes saltos de todo tamaño con rotundos e inesperados cambios de direcciones. Desde ya que observar la sección de Way Station fuera de su contexto original es novedoso, más observándola en simultáneo con la sección de Fielding Sixes, totalmente opuesta 
tanto en la cantidad de intérpretes como en el tipo de movimientos ejecutados (refiriéndome a sus calidades específicas como al estilo de los mismos). Si a esto le sumamos que en otro escenario se sucede una sección de Doubles (1984), el panorama parece complejizarse todavía más.

\section{Hacia una posible definición}

Para avanzar en la problematización del estatuto de estas construcciones, resulta pertinente abordar lo que Oscar Steimberg plantea en relación con los géneros, categoría que remite a aquellas clasificaciones que crea la sociedad para organizar la multiplicidad de producción de sentidos. En sus «Proposiciones sobre el género», Steimberg define a los géneros como «clases de textos u objetos culturales, discriminables en todo lenguaje o soporte mediático, que presentan diferencias sistemáticas entre sí y que en su recurrencia histórica instituyen condiciones de previsibilidad en distintas áreas de desempeño semiótico e intercambio social» (2013:49).

Históricamente, dentro de las artes escénicas, la danza se organizaba en una suerte de orquestación jerárquica que generaba una determinada armonía producto de una relación políticamente correcta entre las partes. Las obras de Cunningham, por el contrario, proponen otra impronta lograda a partir de concebir de manera aislada los diversos aspectos que la integraban, dando lugar a que el hecho artístico sea un producto del acontecimiento en lugar de una totalidad construida deliberadamente. Como ya hemos visto en los ejemplos desarrollados, el movimiento, la música, la escenografía, luces y vestuarios son concebidos por separado y de manera autónoma, uniéndose en una presentación donde comparten el mismo espacio y tiempo.

En cuanto al uso del espacio, sus obras escapan a la visión del centro del escenario como punto de mayor intensidad o zona de mayor importancia. Sus obras no tienen un único centro, cada parte del espacio es tratada con la misma importancia. El bailarín se ubica en un punto determinado del espacio y ese punto en ese momento particular es su centro. Esto implica que ya no hay un punto central alrededor del cual se organiza el conjunto sino una infinidad de puntos equivalentes, como lo propone la teoría de la relatividad de Albert Einstein. De esta manera, cada individuo era considerado como el centro de su propio universo. El uso tradicional de un solo frente, que la danza había adoptado por las características del teatro a la italiana en el que usualmente acontecía, también fue roto ya que Merce no priorizaba ningún frente. Esta forma de entender el espacio habilita en sus obras un funcionamiento multi direccional en el que se utilizan por igual las ocho direcciones espaciales, lo que resulta en una apertura total del espacio. Las coreografías de Cunningham no proporcionan un único punto de atención o una orientación sobre dónde o cómo mirar: cada espectador debe tomar sus propias decisiones ya que en cualquier momento pueden haber varias cosas sucediendo al mismo tiempo en distintas partes del espacio y ninguna será más relevante que la otra.

$\mathrm{Al}$ observar cualquier obra de ballet clásico resulta fácil vislumbrar cómo el cuerpo de baile generalmente crea un marco visual organizándose simétricamente alrededor de los bailarines principales. Si bien se podría argumentar que en este caso también el espectador debería verse obligado a elegir observar a los solistas o al cuerpo de baile, si pensamos la relación entre estos actores dentro de una operatoria de figura-fondo, resulta claro hacia donde habrá que llevar la atención y eso está ligado a un ordenamiento jerárquico en el cual encontramos (de menor a mayor categoría) al cuerpo de baile, los corifeos, solistas, primeros bailarines y etoiles. La MCDC, por el contrario, no tiene una jerarquía explícita, sino que está compuesta por distintos individuos 
que son tratados esencialmente como iguales. Desde ya que dentro de sus obras aparecen solos, dúos, tríos y conjuntos más numerosos, pero todos los bailarines participan de cualquier tipo de configuración y cualquier tipo de configuración tiene la misma relevancia que el resto.

Cunningham liberó a la danza de las grandes determinaciones que regían sobre ella desde el surgimiento de los ballets de corte en el siglo XVI, introduciendo transformaciones en la manera de concebir sus elementos esenciales. En toda su obra opera un cambio en los motivos y temas desarrollados. Como el mismo Cunningham señala:

En mi trabajo coreográfico, la base de las danzas es el movimiento, es decir, el cuerpo humano moviéndose en el tiempo y en el espacio. (...) Las ideas de la danza proceden del movimiento y, a la vez, están en el movimiento. No tiene ninguna otra referencia. (1970:52)

Al concebir a la danza como movimiento en tiempo y espacio, la búsqueda del artista no está signada por una finalidad narrativa, sino que esta remite a sus propios componentes. La utilización de la aleatoriedad fue posible por haber eliminado el deseo de que la danza refiriera a algo externo a la danza. Al no insertarse la obra dentro de un tiempo cronológico, es posible transitar de un punto a cualquier otro, lo que posibilitó también eliminar cualquier noción de personaje, historia e incluso de emoción en la escena. De esta manera Cunningham liberó a la danza no solo de su relación determinante con la música, sino también de la narrativa.

A nivel retórico, aparece un nuevo tipo de configuración de las áreas involucradas y una disrupción en la investigación sobre los propios componentes del movimiento. El mismo Cunningham señala respecto de sus obras que «Una determinada danza no se origina en un pensamiento mío sobre una historia, un estado de ánimo o una expresión: las proporciones de la danza proceden de la actividad en sí» (1970:52). En los lenguajes que utilizan la danza moderna y el ballet, el movimiento surge de impulsos internos (una emoción) o externos (un concepto) para expresar algo ajeno al movimiento mismo, ya fuera una historia o una emoción. En su búsqueda por el movimiento puro Cunningham tuvo que deshacerse de estos lenguajes y crear uno nuevo desechando los métodos empleados en la construcción de estos lenguajes con el fin de trascender aquellos aspectos que la danza moderna no pudo modificar, ya que creó nuevos lenguajes pero fueron construidos sobre las bases existentes, dando por resultado una transformación superficial.

El mismo quiebre que opera en la relación entre las áreas que forman parte de la obra y en la organización de las distintas secciones coreográficas, también se presenta en su forma de concebir el cuerpo en movimiento. Dentro de cualquier frase de movimiento de Cunningham, cada segmento del cuerpo tiene su propio patrón que no necesariamente se condice con los demás: la cabeza, cada brazo, el torso y cada pierna se mueve por separado uno del otro. Esta articulación de diferentes partes del cuerpo una contra la otra, en diferentes direcciones o tempos (aspecto que se ha visto intensificado desde fines de los años 80 a partir de su trabajo con el software LifeForms) y los rápidos cambios de dirección y ritmo son algunas de las características que hacen que la coreografía de Cunningham sea completamente distintiva e identificable.

A nivel enunciativo, aparece un artista que deja de lado la potestad sobre todo lo que acontezca, dejando esa decisión en manos del azar. Esta modalidad se contrapone a la idea del creador inspirado y deja de lado el control consciente que este ejerce sobre la escena. Hay 
una relación de paridad entre las partes en la que cada una conserva su independencia. Estas no se incorporan para establecer una relación jerárquica con la danza: ni la determinan, ni la apoyan, simplemente conviven con ella. Esto implica poner también en crisis la experiencia de los espectadores, quienes tendrán un rol por demás de activo en la construcción del resultado final.

A partir de estos desvíos presentados en los rasgos retóricos, temáticos y enunciativos resulta posible analizar a los Events como una forma de obra antigénero que, siguiendo a Steimberg, se entiende como un tipo de obra que "produce rupturas en los tres niveles sobre la base del mantenimiento de indicadores habituales del género» (2013:85). Los Eventos aparecieron como la vanguardia del trabajo creativo de Cunningham y como tal, su disrupción respecto de las normas de género y estilo provocan una ruptura general de la previsibilidad característica en producciones similares. Es un tipo de propuesta que rompe con las regularidades que habilitan la circulación de las obras escénicas y disuelve la posibilidad de previsibilidad en el encuentro entre la obra y el espectador. Los Eventos le permitieron a Cunningham fragmentar aún más la estructura que ya venía fragmentando, resultando en una ruptura enorme con la práctica coreográfica existente, incluso con la propia.

En la confrontación que realiza entre género y estilo, Steimberg toma de Mijail Bajtin la definición sobre el efecto de previsibilidad que suponen los géneros para referirse a un «horizonte de expectativas» (2013:49) que determina cierto rasgo ligado a qué es lo que el consumidor de una época determinada espera de una obra. El horizonte de expectativas de una obra permite analizar su influencia en una audiencia determinada, pudiendo existir una distancia entre las expectativas del público con relación a determinada producción, lo que habilita la capacidad de modificación de ese horizonte.

Dentro de un ballet, el Grand pas de deux consiste en una sección realizada por los protagonistas de la historia. Esta sección se compone por un conjunto de danzas con un tema común y una estructura estable que, si bien comenzó a forjarse en los ballets de acción del siglo XVIII, debe al coreógrafo Marius Petipa su forma final. La misma se conforma por una entrée, un adagio, una variación masculina, una variación femenina y una coda.

Esta estructura se repite sin demasiadas modificaciones en cualquier obra y corresponden al momento en que la pareja de protagonistas realiza el mayor despliegue de virtuosismo técnico e interpretativo y donde cobra un gran énfasis la masculinidad y fuerza del hombre y la delicadeza y ligereza de la mujer.

En relación con el horizonte de expectativas, el pas de deux representa dentro de un ballet el momento más dramático y de mayor lirismo, allí suele producirse el nudo o el desenlace de la dramaturgia. La entrada opera como un breve preludio donde los bailarines suelen reconocerse entre sí y se posicionan para el adagio posterior. Según las particularidades de la coreografía, los bailarines pueden entrar de manera simultánea o en momentos diferentes. En el adagio, la bailarina realiza movimientos lentos que generalmente implican un gran dominio del equilibrio mientras que el bailarín oficia de sostén, ya sea elevándola por el aire, guiándola en distintas promenades o giros. Una vez completado el adagio, los bailarines se separan para ocupar (de a uno por vez) el lugar central del espacio y realizar su variación. La coda es el segmento final y funciona como una recapitulación de los elementos característicos de los movimientos anteriores. 
Resulta imposible encontrar este nivel de previsibilidad en cualquier producción de Cunningham. Dentro de ellas conviven, al mismo tiempo y en diferentes partes del escenario, secciones sin una aparente relación. Incluso en cualquiera de sus frases, el ritmo puede variar drásticamente de un momento a otro. Sus composiciones al no seguir una historia, escapan también a la estructura convencional de un inicio, un climax posterior y su consecuente descenso. En los pas de deux se observa una serie de indicadores estables que corresponden a determinadas regularidades: una estructura guía, motivos temáticos que remiten a una determinada situación dramática, recursos coreográficos, etc. Los Events, como posibilidad de obra antigénero, quiebran la previsibilidad instalada en los órdenes retóricos, temáticos y enunciativos. En estos casos, la novedad referencial rompe con la costumbre temática de remitir a una historia ajena a la danza; la enunciativa, con la postura que toma el artista con relación a su obra y el tipo de competencias que exige a los espectadores; a nivel retórico, con la ausencia de previsibilidad, dado que el único factor constante que podemos encontrar es el del cambio.

Windows (1995) es una obra que debe su nombre al famoso sistema de «ventanas» que instaló dicho sistema operativo. Estas permiten dividir el espacio de la pantalla y además pueden moverse libremente dentro del mismo. Este aspecto se refleja en la coreografía donde diferentes grupos en diferentes áreas del escenario realizan diversas actividades en variados tempos, pudiendo además fusionarse o dividirse en distintas configuraciones. La obra comienza con el ingreso de tres bailarines y una bailarina que comparten los mismos patrones de locomoción, solo que cada uno de ellos los va repitiendo según un orden particular y en un patrón espacial determinado. La bailarina se desprende de este motivo para comenzar un solo que es asistido por los otros tres bailarines que, una vez cumplida su tarea, retoman el patrón de locomoción inicial. Cuando su solo concluye, ella se retira de la escena junto a dos de los bailarines. Al bailarín que queda se le suman otros cuatro para iniciar la sección de los «tens» que consiste en diez sets de cinco pasos cada uno, intercalando plies y releves a distintas direcciones. Cada set de cada bailarín tiene diferentes combinaciones de posiciones de torso y brazos y un recorrido determinado. Luego del octavo set hay un «break» que consiste en cuatro movimientos comunes a todos, para luego retomar el guión propio. Esta misma sección se repite a lo largo de la obra a distintas velocidades, en parejas, como solos, etc. Más allá de lo complejo de esta estructura compositiva, podremos encontrar que las distintas secuencias coreográficas comparten un mismo vocabulario de movimiento. En un Evento, debido a la convivencia y yuxtaposición de materiales de diversas características, esta complejidad y la sensación de discordancia se amplían de una forma exponencial.

\section{Trascender las prácticas}

Al abordar el planteo sobre el estatuto de los Events, me resulta inevitable trazar ciertas comparaciones entre este tipo de construcciones y el discurso producto de una práctica curatorial. Un discurso curatorial propone una determinada modalidad de visibilizar el arte y supone una forma particular en cómo este será recibido por el público, además de implicar la creación de una nueva dinámica de relaciones entre los diferentes actores que se conjugan en este proceso. Partiendo de la pauta de incluir segmentos de obras pasadas en nuevos discursos, podemos pensar que los Events comparten la impronta de cualquier trabajo curatorial de expandir, multiplicar e incluso abrir caminos inéditos en la percepción de una obra (en este caso, fragmentos de ellas), formulando nuevas lecturas, relaciones y dispositivos de exhibición. 
A finales de la década de 1980 hubo un cambio en la noción de curaduría que pasó de ser concebida como una actividad administrativa y mediadora hacia una actividad creativa y artística cuyo proceso era posible de comparar con el de los readymades duchampianos. Lo que esto implica según Paul O'Neill (2007), un pasaje de una jerarquía cultural centrada en el autor hacia un discurso posproductivo, en el que la función del curador se ha convertido en otra parte reconocida del campo expandido de la producción artística. En la naturaleza propia de los Events, los fragmentos/detalles expuestos son, de alguna forma, ajenos a la obra en la que están participando. Si el artista al producir un Event reutiliza sus propios materiales bajo un criterio particular, la distancia que le separa en su quehacer del trabajo de un curador no es tan amplia. El curador construye un sistema o estructura que se halla relacionado con el tiempo y el espacio y depende de ellos; al igual que el coreógrafo, diseña el ritmo de una exposición y estructura su temporalidad, trabajando sobre cómo determinadas sucesiones de materiales de movimientos se presentan durante la exposición/performance. En los Events, la exposición de los materiales es un acontecimiento en sí mismo que tiene el estatus de hecho creativo y conforma una producción artística. Quizás esto nos permite trazar una correspondencia entre la práctica coreográfica y la actividad curatorial en la definición, el diseño y la construcción del espacio donde convergen el flujo de objetos, sujetos y experiencias.

Un aspecto fundamental de la estrategia compositiva de Cunningham, que guarda relación con la operatoria propia de la práctica curatorial, se encuentra ligado al hecho de que la experiencia de lo que vemos y oímos es contextual. Marcelo Pacheco toma de Arthur Danto una serie de conceptos que señala como fundamentales para pensar la práctica curatorial como un «ejercicio de escritura narrativa y de organización histórica» (2001:4). Allí propone que:

Los acontecimientos, en el sentido histórico del término, se rescriben continuamente y se reevalúa su significación a la luz de información posterior. El mismo acontecimiento tendrá una significación diferente de acuerdo con el relato (story) en que se sitúe o, dicho de otro modo, de acuerdo con qué diferentes conjuntos de acontecimientos posteriores pueda estar conectado. (2001:4-5)

Esto da cuenta de cómo el trabajo curatorial favorece la apertura de cualquier obra de arte a través de los múltiples significados que el curador pueda estimular. Este tipo de práctica cobra entidad a partir de este dispositivo artístico que no solamente exhibe, sino que además problematiza y expande la construcción de sentido de las diferentes obras que lo componen. Al insertar diferentes segmentos dentro de un nuevo discurso, con una forma particular de organizar las partes y las nuevas conexiones y relaciones que surjan dentro del campo de escritura escénico, podemos pensar que sus Eventos operan de la misma manera que una práctica curatorial que "con su capacidad de envolver y trastocar los textos instituidos, muestra aristas, agrega texturas y propone cantos paralelos que se multiplican, tejiendo otras miradas» (Pacheco, 2001:5). Al referir la práctica curatorial como un «campo de escritura», se habilita la posibilidad de que la construcción de sentido de las obras pueda continuar sucediendo de una manera que pareciera no tener fin. Su inclusión dentro de un nuevo marco de relaciones permite delinear nuevas lecturas, observar otros aspectos y favorecer a que la producción de sentido siga activa a partir de conectar, relacionar y organizar unidades diversas gracias a su capacidad de desplazamiento. 


\section{Conclusión}

El Event es un formato que presenta una serie de desvíos en relación con los rasgos retóricos, temáticos y enunciativos de otras prácticas escénicas que habilitan la posibilidad de concebirlos como tipos de obra anti-género y que además, pone sobre la mesa ciertos aspectos de las figuras del artista y el curador para plantear puntos de contacto en el tipo de trabajo que realizan y por ende entre las producciones resultantes de ellos: la práctica artística y la práctica curatorial. La práctica curatorial fue descripta por Pacheco como una actividad que:

No fija objetos, sino que se desliza incierta abriendo campos de relaciones. En toda exposición algo es expuesto públicamente mediante un gesto que se repite y se multiplica sobre textos ya existentes. El acto de exponer debe ser considerado un acto discursivo y, como refuerza Bal, una demostración pública. Se trata de un dispositivo que narra en el espacio, espacio físico, espacio social, espacio simbólico. (2001:4)

Este gesto expositivo implica el desarrollo creativo del marco conceptual de la exhibición, la construcción de sentido a partir de un conjunto determinado de obras y la consecuente articulación entre el espacio expositivo y el marco conceptual para lograr los objetivos propuestos. La práctica curatorial, al igual que la práctica artística, implica poner en práctica diversos aspectos creativos para lograr determinada construcción de sentido a través del discurso propio.

Resulta evidente al analizar la utilización del Evento como dispositivo exhibitivo, la manera en que las tareas del curador y del artista aparecen entrecruzadas, por lo que los límites que separan la especificidad entre el crear y el curar parecieran disiparse. En el corpus analizado es notorio cómo las decisiones que toma el artista/curador (en especial, las relacionadas al uso del espacio exhibitivo y a las estrategias compositivas empleadas) modifican de lleno la experiencia de acceder a determinado patrimonio, logrando una novedosa relación entre los materiales presentados y la experiencia de los espectadores. De esta manera, en momentos específicos de su trabajo, Cunningham opera tácticamente como un curador, haciendo uso de mecanismos metadiscursivos que suponen un notorio contraste con otras prácticas escénicas.

Hoy en día, la curaduría dejó de ser solamente una actividad tradicional de museos y centros culturales, sino que puede presentarse en cualquier tipo de relato que regule un conjunto de objetos que el ser humano posea. Usualmente, para la creación de un discurso curatorial, el curador se vale de obras que le son ajenas, combinándolas de una manera determinada que le permite ofrecer una nueva lectura. Cunningham realizó esta misma operación con el reciclado de sus propios materiales a través de su reordenamiento en nuevas situaciones con características específicas. El complejo dispositivo expositivo que proponen los Eventos favorece la circulación de los materiales del artista por senderos múltiples que en lugar de fijar su sentido, expande sus límites al ponerlos en nuevas relaciones de coexistencia.

La curaduría ha roto los límites tradicionales para estar presente en múltiples prácticas que ya no son las específicas de las artes visuales, proponiendo ciertos desordenes y contaminaciones que favorecen la creación de nuevos artefactos culturales. La estrategia compositiva de Cunningham con los Events opera en la misma sintonía que cualquier proyecto curatorial, permitiéndonos plantearlos no solo como posibilidad de obra anti-género sino también, como un novedoso dispositivo exhibitivo propio de las artes escénicas que favorece la puesta en jaque de la tajante división que pareciera haber entre una producción artística y una producción curatorial. 


\section{Referencias}

Cunningham Dance Foundation, Inc. (2012). The Legacy Plan. A Case Study. New York.

Cunningham, M. (1970). Choreography and the dance. En Rosner, S. (ed.). The Creative Experience (Grossman, New York). Reeditado en Steinberg, C. (ed.). The Dance Anthology (52-62). Nueva York: A Plume Book of New American Library, Inc.

Cunnningham, M. (1994). Four Events That Have Led to Large Discoveries. Merce Cunningham: Fifty Years 276. Nueva York: Aperture Press.

Crimp, D. (2008). Dancers, Artworks, and People in the Galleries. Artforum, 47, 347-407.

Crimp, D. (2012). Park Avenue Armory Event. Nueva York: Cunningham Dance Foundation and ARTPIX.

Genter, S. (2008). Beacon Event. Ballet Review, Fall 2008, 70-88.

Lesschaeve, J. (2009). El bailarín y la danza: Conversaciones de Merce Cunningham con Jacqueline Lesschaeve. Barcelona: Global Rhythm Press, S.L.

O'Neill, P. (2007). The curatorial turn: from practice to discourse. En Rugg, J. y Sedgwick, M. (eds.). Issues in Curating Contemporary Art and Performance (13-28). Chicago: Intellect Books.

Pacheco, M. (2001). Campos de batalla... Historia del arte vs. Práctica curatorial. Ponencia leída en el simposio Teoría, Curatoría, Crítica, organizado por la Pontificia Universidad Católica de Chile, Santiago, Chile.

Rabadan, A. (2008). El cuerpo. Una conceptualización desde la danza nueva. Tesis para obtener el grado de Maestra en Filosofía de la Cultura, Facultad de Filosofía, Universidad Michoacana de San Nicolás Hidalgo, Morelia, Michoacán, México.

Steimberg, O. (2013). Proposiciones sobre el género. En Steimberg, O. Semióticas: las semióticas de los géneros, de los estilos, de la transposición (46-96). Buenos Aires: Eterna Cadencia. 